\title{
O COMANDO VERMELHO E A ORDEM MUNDIAL
}

\author{
Dirceu Ricardo Lemos Ceccatto*
}

\section{RESUMO}

O presente artigo tem por objetivo apresentar as relações existentes entre o Comando Vermelho e a ordem mundial. Inicialmente, o foco da pesquisa está voltado para as idéias de Cox sobre as estruturas históricas e de Gramsci sobre as sociedades civil e política. Em seguida, a abordagem é voltada para a formação do Comando Vermelho, analisando-a a partir das estruturas históricas e levando em consideração as modificações na ordem mundial. Conclui-se que o Comando Vermelho foi influenciado em sua formação pelo Estado, transformando a sociedade civil com a sua presença, observando a sua importância nos desdobramentos da ordem mundial.

Palavras-chave: Comando Vermelho. Estruturalismo histórico. Crime organizado.

\begin{abstract}
The present paper has as its main objective to analyze the contemporarily relations between the Red Command and the new international order. Initially, the research focuses on the ideas of Cox about the historical structures, as well as Gramsci analysis of civil society and politics. Secondly, the paper shows the implementation of the Red Command, analyzing its historical background and taking into consideration the changes of the world order. As a conclusion, it is stated that the Red Command was influenced by the State since its beginning, transforming the civil society with its presence, including the observation of its importance in a context of contemporarily new order.
\end{abstract}

Key-words: Red Command. Historical structuralism. Organized crime.

\footnotetext{
* Graduado em Relações Internacionais pelo Centro Universitário de Brasília UNICEUB.
} 


\section{INTRODUÇÃO}

O mundo do século XX se caracterizou por inúmeras transformações em sua ordem mundial. Como conseqüência dessas modificações, novas formas de Estado foram sendo estabelecidas, concomitantemente, novas forças sociais surgiram e outras foram transformadas. Podemos afirmar que todas as modificações foram moldadas a partir das ontologias de cada região.

No Brasil, no período da ditadura militar, mais precisamente no Governo Costa e Silva, um novo ator surge. A princípio, sua presença não é tão relevante no cenário político nacional e internacional. Entretanto, com o passar dos anos, ganha força, respeito e importância: o Comando Vermelho passa a ganhar espaço.

Para entender melhor o assunto que este artigo pretende abordar, o trabalho foi dividido em três partes: a primeira faz referência às estruturas históricas de Robert Cox, a segunda fala sobre a formação do Comando Vermelho e a terceira, sobre as relações entre o Comando Vermelho e a ordem mundial.

Para viabilizar este estudo, foram formuladas duas questões a serem respondidas na segunda e na terceira parte com subsídios das estruturas históricas que serão apresentadas: como o Comando Vermelho é formado por elementos constantes na 
ordem mundial e no Estado brasileiro? Como a atuação do Comando Vermelho gera mudanças na Ordem Mundial e no Estado brasileiro?

A proposta central é suscitar a reflexão sobre as consequiências da criação e atuação do Comando Vermelho nas modificações ocorridas na ordem mundial, na formação do Estado e nas forças sociais. Será exposto como os atores e suas ações estão inter-relacionados, pois não podemos fechar os olhos para a gravidade da influência do crime organizado na vida dos indivíduos, na formação das políticas públicas e na construção de uma nova ordem mundial. 


\section{COX E AS ESTRUTURAS HISTÓRICAS}

Esta primeira parte abordará o que vem a ser as idéias de Robert Cox sobre as estruturas históricas, que serão úteis para o entendimento de como elas influenciaram na formação, desenvolvimento e consolidação do Comando Vermelho.

Cox é influenciado por Antonio Gramsci que, quando preso no período fascista na Itália, escreve os Cadernos de Cárcere, uma análise do Estado, por uma visão de um comunista influenciado pela terceira internacional. Em seus estudos, o Estado é analisado por um prisma mais social que econômico. Gramsci entende que o elemento determinante do processo histórico não está voltado para a base econômica e, sim, para o que ele denomina de superestrutura política. ${ }^{1}$

Este autor defende "uma relação dialética de 'identidade-distinção entre sociedade civil e sociedade política', duas esferas da 'superestrutura', distintas e relativamente autônomas, mas inseparáveis na prática". ${ }^{2}$ Dessa forma, temos Estado = sociedade política + sociedade civil.

A sociedade política, também conhecida por Gramsci como "Estado em sentido estrito" ou "Estado-coerção", é "formada pelo conjunto dos mecanismos através dos quais a classe dominante detém o monopólio legal da repressão e da violência e que se identifica com os aparelhos de coerção sob o controle das burocracias executiva e policial militar" ${ }^{3}$ Portanto, a sociedade política tem como características principais o exercício da coerção e a manutenção da ordem estabelecida. ${ }^{4}$

Já a sociedade civil é definida "pelo conjunto das organizações responsáveis pela elaboração e/ou difusão das ideologias, compreendendo o sistema escolar, as Igrejas, os partidos políticos, os sindicatos, as organizações profissionais, a organização material da cultura (revistas, jornais, editoras, meios de comunicação de massa), etc". 5 Vulgarmente é considerada como o conjunto dos organismos privados "que correspondem à função de hegemonia que o grupo dominante exerce em toda a

\footnotetext{
${ }^{1}$ COUTINHO, Carlos N. “Teoria 'ampliada' do Estado”. In: COUTINHO, Carlos N. Gramsci: um estudo sobre o seu pensamento político. Rio de Janeiro: Civilização Brasileira, 2003. p. 122.

2 SEMERARO, Giovanni. "A Concepção da Sociedade Civil”. In: SEMERARO, Giovanni. Gramsci e Sociedade Civil. Rio de Janeiro: Vozes, 1977. p. 74.

${ }^{3}$ COUTINHO, Carlos N., op. cit., p. 127.

${ }^{4}$ PORTELLI, Hugues. "A superestrutura do bloco histórico" In: PORTELLI, Hugues. Gramsci e Bloco Histórico. Rio de Janeiro: Paz e Terra, 1977. p. 33.

${ }^{5}$ COUTINHO, Carlos N., op. cit., p. 127.
} 
sociedade" ${ }^{\prime 6}$, desse modo, todas as formas de influência sobre uma sociedade, por parte de um grupo dominante, é denominada sociedade civil.

Para que a sociedade civil atue é necessário que ela exerça influência direta nos indivíduos que a compõem. Gramsci vê o papel da propagação das idéias por parte dos intelectuais orgânicos que são vistos como organicamente conexos à classe social. Os intelectuais burgueses criam uma imagem cultural única para a burguesia, enquanto são considerados hegemônicos. Já os intelectuais orgânicos, junto com a sociedade civil, travam uma batalha pela hegemonia: "they perform the function of developing and sustaining the mental images, technologies and organizations which bind together the members of a class and of an historic bloc into a common identity".

Para Gramsci, todos somos, de alguma forma, intelectuais, já que essa idéia do intelectual orgânico passa pela noção de líderes influentes dentro de uma determinada sociedade como, por exemplo, líderes sindicais, prefeitos de quadras, representantes de turma, líderes comunitários de favelas, entre outros.

Portanto, toda filosofia orgânica deve ser propagada por meio do senso comum, "qualquer movimento filosófico orgânico deve permanecer em contato com as camadas populares, os 'simples', e precisa inclusive situar nesse contato, 'a fonte dos problemas a estudar e resolver' a fim de melhor dirigir ideologicamente as classes subalternas". 8 necessidade de utilizar o senso comum ao invés da filosofia se dá em função desta retratar "os traços individuais do pensamento", enquanto aquele, os "traços difusos de certa época e de um certo meio popular". ${ }^{9}$ Cada camada ou grupo social possui sua própria concepção de senso comum.

A partir dos pensamentos gramscianos, Cox "não aceita considerar as instituições e as relações de poder como dadas e passa a questionar suas origens e como podem ser modificadas". ${ }^{10}$ Para entender as ordens mundiais que se sucederam em períodos históricos distintos, três categorias de força, conhecidas como estruturas históricas, são apresentadas por Cox, são elas: as capacidades materiais ${ }^{11}$, as idéias ${ }^{12}$ e a institucionalização ${ }^{13}$.

\footnotetext{
${ }^{6}$ PORTELLI, Hugues., op. cit., p. 21.

${ }^{7}$ COX, Robert W. "Gramsci, Hegemony and International Relations: an Essay in Method" In: GILL, Stephen. Gramsci, Historical Materialism and International Relations. Cambridge: University Press, 1993. p. 57.

${ }^{8}$ PORTELLI, Hugues., op. cit., p. 25.

${ }^{9}$ Ibidem. p. 26.

${ }^{10}$ SAFARTI, Gilberto. “Teoria Crítica”. In: SAFARTI, Gilberto. Teoria das relações internacionais. São Paulo: Saraiva 2005. p. 252.

11 As capacidades materiais "dizem respeito à esfera econômica da estrutura social" (SILVA, Marco
} 
Essas estruturas históricas ficam mais claras quando são aplicadas em três níveis: formas de Estado, forças sociais e ordens mundiais. "A interação desses três níveis proíbe qualquer hierarquia determinada a priori das relações. Além do mais, cada nível é resultado da luta entre estruturas rivais". ${ }^{14}$

O primeiro nível é o que abrange as formas de Estado, que é "derivada do estudo dos complexos sociais e estatais" 15 , ou seja, "a historicidade da forma de qualquer Estado é uma derivação da configuração particular das capacidades materiais, idéias e instituições, que é específica de um complexo Estado/sociedade". ${ }^{16}$ O segundo nível é o das forças sociais, que são construídas a partir do processo de produção. Um exemplo disso é que os sindicatos estão se enfraquecendo em favor do fortalecimento de investidores privados. ${ }^{17} \mathrm{E}$ o último nível, o das ordens mundiais. Estas determinam, simplesmente, a forma como os Estados interagem uns com os outros. "Cada contexto histórico produzirá uma configuração específica das forças sociais, dos Estados e da inter-relação entre eles que repercutirá como uma ordem mundial particular". ${ }^{18}$

Esses três níveis interagem entre si, onde o movimento de um influencia na movimentação do outro. São dependentes, já que, hoje, um não existe sem o outro, "seriam inter-relacionados à medida que, por exemplo, as mudanças nas formas de

Antonio de Meneses. "Teoria Crítica em Relações Internacionais". In: Contexto Internacional, vol. 27, $\mathrm{n}^{\circ}$ 2, julho/dezembro de 2005. p. 263), e podem ter um potencial produtivo ou destrutivo, "na medida em que o desenvolvimento tecnológico pode tanto produzir bens duráveis e não-duráveis quanto armamentos" (SAFARTI, Gilberto. "Teoria Crítica". In: SAFARTI, Gilberto. Teoria das relações internacionais. São Paulo: Saraiva 2005. p. 254), drogas mais potentes, facilidades na lavagem de dinheiro etc.

${ }^{12}$ As idéias podem ser vistas de duas formas: significados intersubjetivos, que "afetam a conservação de hábitos e subsidiam expectativas quanto ao comportamento social" (SILVA, Marco Antonio de Meneses. "Teoria Crítica em Relações Internacionais". In: Contexto Internacional, vol. 27, $\mathrm{n}^{\circ} 2$, julho/dezembro de 2005. p. 263), e imagens coletivas, diferenças sociais sustentadas por uma sociedade, ou seja, "as diferentes visões sobre a natureza e a legitimidade das relações de poder compartilhadas por grupos específicos como etnias, gênero sexual etc" (SAFARTI, Gilberto. "Teoria Crítica”. In: SAFARTI, Gilberto. Teoria das relações internacionais. São Paulo: Saraiva 2005. p. 254). Dessa forma, há de se convir que os "significados intersubjetivos tendem a ser largamente generalizados em dado contexto histórico, as imagens coletivas são significativamente mais numerosas e divergentes" (SILVA, Marco Antonio de Meneses. "Teoria Crítica em Relações Internacionais". In: Contexto Internacional, vol. 27, $\mathrm{n}^{\circ} 2$, julho/dezembro de 2005. p. 264).

${ }^{13} \mathrm{~A}$ institucionalização é o meio pelo qual as ordens dominantes são perpetuadas à medida que refletem as relações de poder (SAFARTI, Gilberto. "Teoria Crítica". In: SAFARTI, Gilberto. Teoria das relações internacionais. São Paulo: Saraiva 2005. p. 254), entretanto, "podem também transcender a ordem original e influenciar o desenvolvimento de novas idéias e capacidades materiais" (SILVA, Marco Antonio de Meneses. "Teoria Crítica em Relações Internacionais". In: Contexto Internacional, vol. 27, $\mathrm{n}^{\circ}$ 2, julho/dezembro de 2005. p. 264).

${ }^{14}$ SILVA, Marco Antonio. "Teoria Crítica em Relações Internacionais". In: Contexto Internacional, vol. 27, ${ }^{\circ} 2$, julho/dezembro de 2005. p. 264.

${ }^{15}$ SAFARTI, Gilberto., op. cit., p. 254.

${ }^{16}$ SILVA, Marco Antonio., op. cit., p. 264.

${ }^{17}$ Idem.

${ }^{18}$ Idem. 
produção gerariam novas forças sociais que, por sua vez, modificariam as estruturas do Estado e levariam a alterações das ordens mundiais". ${ }^{19}$

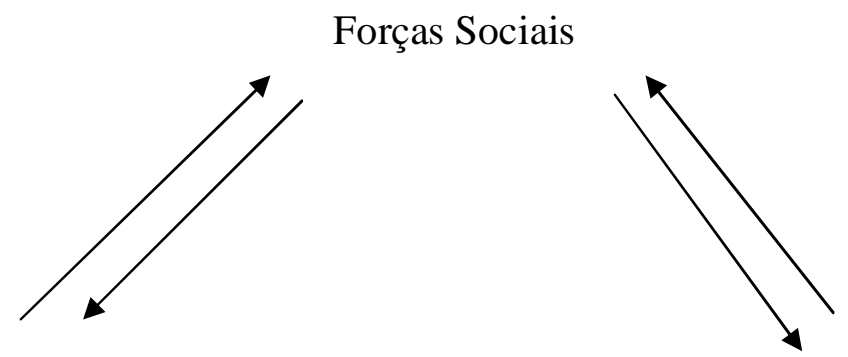

Formas de Estado

Ordens Mundiais

Diante do que foi apresentado, podemos concluir que os pensamentos de Gramsci foram muito importantes para a formação do pensamento de Cox e que o estruturalismo histórico é uma ferramenta importantíssima para que se possa entender como as ordens mundiais, as formas de Estado e as forças sociais interagem entre si. Cada momento histórico é influenciado por um desses níveis. No caso do Comando Vermelho, esses níveis são fatores essenciais para entender de que forma essa instituição se formou, como ela se consolidou e de que modo ela se torna influente dentro das estruturas históricas.

${ }^{19}$ SAFARTI, Gilberto., op. cit., p. 254. 


\section{A FORMAÇÃO DO COMANDO VERMELHO}

Com o final da Segunda Guerra Mundial, o mundo entrou em uma nova ordem mundial conhecida como Guerra Fria, um período em que Estados Unidos e União Soviética mediam forças e buscavam cada vez mais expandirem suas áreas de influência em todo o mundo. Estes dois países foram responsáveis pela disseminação de suas ideologias e, para tal, utilizaram meios como a criação, o apoio e o financiamento dos partidos políticos, bem como dos governos dos Estados.

No caso brasileiro, especificamente, os partidos comunistas eram financiados pelo Estado soviético. Nesse período, alguns líderes se firmaram e outros novos entraram em cena, como foi o caso de Luiz Carlos Prestes e de Olga Benário, que aparecem como atores importantes da Era Vargas. No entanto, os movimentos revolucionários de esquerda só começam a se firmar de fato a partir das greves operárias em Belo Horizonte e Osasco, em 1968, esta última influenciada por grupos que tinham assumido a posição de que somente com a luta armada o regime militar chegaria ao fim.

Apenas com o emprego de muita violência, por parte do Governo Costa e Silva, os operários desocuparam a empresa de Osasco. "Esses grupos foram muito influenciados pelo exemplo da Revolução Cubana e pelo surgimento de guerrilhas em vários países da América Latina, como Guatemala, Colômbia, Venezuela e Peru". ${ }^{20} \mathrm{O}$ tradicional Partido Comunista Brasileiro (PCB) opunha-se à luta armada, todavia, os radicais romperam com o partido e formaram a Aliança de Libertação Nacional (ALN). Simultaneamente, novos grupos foram surgindo como a Vanguarda Popular Revolucionária (VPR), que era composta em grande parte por militares da esquerda. ${ }^{21}$

Em 13 de dezembro de 1968, o então Presidente Costa e Silva baixa o AI-5 (Ato Institucional $\mathrm{n}^{\circ} 5$ ). No ano seguinte, é realizada a reforma na Lei de Segurança Nacional (LSN), o Artigo 27 do Decreto-Lei 898 “agravava as penas para assalto, roubo e depredação nas instituições financeiras e de crédito, estes crimes deixavam de ser julgados pelo Código de Processo Penal e passavam para o âmbito dos tribunais militares". 22 As penas aumentaram para dez a vinte e quatro anos de prisão. Dessa forma, foram criados os Destacamentos de Operações e Informações da Coordenação de

\footnotetext{
${ }^{20}$ FAUSTO, Boris. História Concisa do Brasil. 2 ed. São Paulo: Editora da Universidade de São Paulo 2006. p. 264.

${ }^{21}$ Idem.

${ }^{22}$ AMORIM, Carlos. CV-PCC: a irmandade do crime. 6 ed. Rio de Janeiro: Record, 2005. p. 60.
} 
Defesa Interna (DOI-CODI), que eram os responsáveis por investigar os principais grupos da esquerda revolucionária.

O governo militar tentou despolitizar as ações armadas da esquerda, tratando-as como 'simples banditismo comum', o que permitia também uma boa argumentação para enfrentar as pressões internacionais em prol da anistia e contra a tortura. Nivelando o militante e o bandido, o sistema cometeu um grave erro. $\mathrm{O}$ encontro dos integrantes das organizações revolucionárias com o criminoso comum rendeu um fruto perigoso: o Comando Vermelho. ${ }^{23}$

A modificação da forma de atuação do Estado transformou as forças sociais que eram altamente influenciadas pelo contexto da ordem mundial. Dessa forma, as atitudes do Estado brasileiro foram responsáveis pelo aumento dos movimentos armados da esquerda brasileira, "os guerrilheiros, (...) estabeleceram ligações com os camponeses, ensinando-lhes métodos de cultivo e cuidados com a saúde". ${ }^{24}$ Mobilizações do exército mataram e prenderam os revolucionários, distribuindo-os entre os presídios brasileiros.

Em seguida, quando os revolucionários de esquerda chegam ao presídio de Cândido Mendes, em Ilha Grande, Rio de Janeiro, ficam confinados na Ala B, também conhecida como "fundão", ala reservada aos presos comuns. Nessa época, o presídio era dominado pela Falange do Jacaré, que escolhia entre os novos presos quem seriam os soldados e quem iria "virar mulher". 25

No "fundão", os presos políticos pregavam o socialismo e ensinavam técnicas de guerrilha para os presos comuns. Nesse momento, nasce o Comando Vermelho (CV), que chega para conter as atrocidades que eram cometidas dentro do presídio e para dar alguns direitos aos presidiários. Não demorou muito tempo e eles dominaram o presídio de Ilha Grande. ${ }^{26}$

A influência dos líderes do $\mathrm{CV}$ sobre os presidiários era muito forte. Eram pessoas com alta capacidade intelectual, como o Padre Alípio Cristiano de Freitas, "convencido de ter uma missão entre os homens: fazer a revolução socialista no Brasil". ${ }^{27}$ Muito envolvido com a formação de líderes sociais, fez parte do Secretariado das Ligas Camponesas. Sua influência dentro do presídio era incomum, todos o adoravam e respeitavam não só pela sua inteligência, mas também por ter dado um tapa

\footnotetext{
${ }^{23}$ Ibidem. p. 58.

${ }^{24}$ FAUSTO, Boris., op. cit., p. 267.

${ }^{25}$ Estratégia de dominação dentro do presídio.

${ }^{26}$ AMORIM, Carlos, op. cit., pp. 60-65.

${ }^{27}$ Ibidem. p. 77.
} 
na cara de um torturador do DOI-CODI em pleno interrogatório. ${ }^{28}$ As idéias do padre eram aceitas pelos presidiários tornando-o um líder ou, em uma visão gramsciana, um intelectual orgânico, já que suas idéias poderiam ser de significado intersubjetivo, por ter o monopólio ideológico dentro do instituto e de imagens coletivas, por divergir das idéias governamentais.

Os intelectuais orgânicos do CV eram conhecidos como professores. Quando dominaram o presídio de Ilha Grande, aderiram ao seguinte slogan para a organização, mais tarde também utilizado pelo Primeiro Comando da Capital (PCC): "Paz, Justiça e Liberdade". A partir daí, o CV ganha força, porque além de tornar a vida do preso mais "tranqüila", financiava fugas e entrada de droga nos presídios.

Para financiar as fugas começaram a realizar assaltos a banco, mesma tática utilizada pelos movimentos esquerdistas brasileiros para reunir fundos conhecidos como “expropriações”, onde, pela primeira vez, ouviu-se falar do CV.

José Jorge Saldanha, o Zé do Bigode, enfrentou sozinho um cerco de mais de 400 policiais. Resistiu durante onze horas, até ser morto com um tiro de carabina calibre 12. Especializado em roubar bancos, foi um dos primeiros líderes do CV. Morava justamente no Conjunto Habitacional dos Bancários, onde obtinha informações e planejava seus crimes. ${ }^{29}$

Esse episódio ficou muito conhecido por ter sido transmitido pela TV aberta e por mostrar até onde os ideais revolucionários podiam levar um indivíduo. O Saldanha morreu pelo crime e pelos ideais do $\mathrm{CV}$ que ajudou a formular. Para continuar financiando as fugas dos presídios, o CV entra no ramo do tráfico de drogas, dominando grande parte dos morros da cidade do Rio de Janeiro.

Em 1986, José Carlos dos Reis Encina, mais conhecido como "Escadinha", um dos líderes do CV, foge do presídio de Ilha Grande de helicóptero. No mesmo ano, ele expande os negócios. "O primeiro acerto para importação de cocaína é firmado em Medellín, na Colômbia. Pablo Escobar, o maior traficante do mundo, é quem vai fornecer para o crime organizado no Rio de Janeiro". ${ }^{30}$ Os pacotes de cocaína vindos da Colômbia eram inconfundíveis, já que vinham carimbados com o seguinte slogan: "los nada que ver" e, outras vezes, como "Fortuna - 100\% Pura". 31

\footnotetext{
${ }^{28}$ Idem.

${ }^{29}$ Ibidem. pp. 266-267.

${ }^{30}$ Ibidem. p. 235.

${ }^{31}$ Idem.
} 
Dessa forma, o Comando Vermelho se insere no crime organizado transnacional ${ }^{32}$, transformando-se em um grande parceiro das principais organizações criminosas do mundo como os cartéis colombianos. ${ }^{33} \mathrm{O}$ narcotráfico passa a ser um nicho preocupante na América do Sul a partir o momento em que a já estruturada máfia italiana, no início da década de 1970, envia dois mafiosos da família Cuntrera-Caruana à "Venezuela para tecer a rede de um gigantesco tráfico de drogas". 34 A partir desse momento, essa região torna-se uma base importante para a máfia. "Na rede dos tráficos e dos negócios, o sulamericano começa a representar um núcleo importante". 35

O fim dos anos 70 representa um momento de boom sem precedentes no comércio da droga, que se desenvolve sempre entre os dois mundos, o novo (a América do Sul) e o velho (Europa e Estados Unidos), do qual Buschetta seria um dos boss. Do novo, chegam rios de dinheiro, pelos canais bancários que representam a pista sobre a qual é colocado o novo sabujo da procuradoria de Palermo, o juiz Giovanni Falcone, graças à sua experiência em delitos financeiros. Do velho, partem rios de heroína, com o qual em 1982 se chega a cobrir $80 \%$ do mercado da zona norte-oriental dos Estados Unidos. ${ }^{36}$

Tommaso Buscetta é considerado o "boss dos dois mundos" pelo "seu constante movimento entre a Europa, América do Sul e a América do Norte". ${ }^{37}$ Na década de 1980, o tráfico de drogas gera, para a máfia italiana, bilhões de dólares, divididos entre os membros da Cosa Nostra. ${ }^{38}$ Buscetta acaba preso no Rio de Janeiro no final da década de 1980.

Dessa forma, fica claro que o Comando Vermelho foi influenciado pela ordem mundial vigente e pelas formas de Estado, já que, no período da Guerra Fria, foi fundamental entender de que forma o Estado brasileiro posicionou-se com relação aos grupos de esquerda no país, resultando na reforma da LSN e, em seguida,

\footnotetext{
${ }^{32}$ De acordo com o artigo $3^{\circ}$ inciso $2^{\circ}$ da Convenção das Nações Unidas contra o Crime Organizado Transnacional, o crime só será de caráter transnacional se for cometido: em mais de um Estado; num só Estado, mas uma parte substancial da sua preparação, planejamento, direção e controle tenha lugar em outro Estado; num só Estado, mas envolva a participação de um grupo criminoso organizado que pratique atividades criminosas em mais de um Estado; ou for cometido num só Estado, mas produza efeitos substanciais noutro Estado.

${ }^{33}$ Para saber mais sobre os Cartéis Colombianos ler: RICHARDS, James R., 1960 - Transnational criminal organizations, cybercrime \& money laundering: a handbook for law enforcement officers, auditors, and financial investigators. Florida: CRCPRESS, 1998.

${ }^{34}$ LUPO, Salvatore. História da Máfia: das origens aos nossos dias. Tradução de Álvaro Lorencini. São Paulo: Editora UNESP, 2002. p. 360

${ }^{35}$ Ibidem. p. 366.

${ }^{36}$ Ibidem. pp. 374-375.

${ }^{37}$ Ibidem. p. 373.

${ }^{38}$ Ibidem. p. 377.
} 
proporcionando o "casamento" entre os intelectuais de esquerda e os criminosos comuns.

Além da Guerra Fria, o fascismo italiano foi importante para a inserção do Comando Vermelho no mundo, já que o combate aos mafiosos na Sicília se deu somente no momento em que Mori foi nomeado por Mussolini como o novo Prefeito da cidade de Palermo. A partir desse período, os mafiosos fugiram da Itália e se estabeleceram nos Estados Unidos da América, onde começaram a surgir, a partir de 1920, Al Capone, em Nova Orleans, e Salvatore "Lucky" Luciano, em Nova Iorque, dominando o crime nessas cidades, um negócio que já girava na casa dos milhões de dólares.

Porém, junto com tanto dinheiro vieram as guerras entre as gangues para dominarem as cidades, que geraram centenas de mortes. Em 1931, as dez maiores famílias mafiosas fizeram um conselho ${ }^{39}$ e decidiram dividir o país em dez regiões de influência. ${ }^{40}$ Nova Iorque, por exemplo, foi dividida em cinco áreas de influência. ${ }^{41}$ Cada região foi dominada por uma família distinta, porém, com um líder único, fundando assim a Cosa Nostra, uma vez que as disputas não eram vantajosas para os negócios.

Com o aumento dos negócios da máfia italiana, o Comando Vermelho tornou-se um grande parceiro econômico dos cartéis colombianos, uma rede em que os lucros foram exorbitantes ajudando a firmar o $\mathrm{CV}$ no cenário nacional e também no internacional, além de financiar fugas de presidiários até em helicópteros.

Desse modo, podemos afirmar que o $\mathrm{CV}$ foi fruto da forma como o Estado brasileiro agiu nesse período que, por sua vez, foi modificado pela ordem mundial vigente. Essa força social foi modificada, porém, os movimentos continuam e as tendências são novas modificações que veremos no próximo tópico.

\footnotetext{
${ }^{39}$ Estavam presentes nesse conselho: Lucky Luciano, Meyer Lansky (credited by many as the first to master the concept of laudering money), and Bugsy Seugel (the first to build a major casino in Las Vegas). RICHARDS, James R. Transnational criminal organizations, cybercrime \& money laundering: a handbook for law enforcement officers, auditors, and financial investigators. Florida: CRCPRESS, 1998. p. 6

${ }^{40}$ RICHARDS, James R. Transnational criminal organizations, cybercrime \& money laundering: a handbook for law enforcement officers, auditors, and financial investigators. Florida: CRCPRESS, 1998. p. 6.

${ }^{41}$ Ver filme: O Poderoso Chefão. Título original: The Godfather, 1972. Paramount Pictures. Direção: Francis Ford Coppola.
} 


\section{O COMANDO VERMELHO E A ORDEM MUNDIAL}

O Comando Vermelho teve como marco de sua inserção no cenário mundial o momento em que a máfia italiana chegou à América do Sul com o intuito de organizar o negócio mais lucrativo do mundo, o tráfico de drogas, quando o CV se mostra um importante ponto na rede do crime organizado transnacional, com a função de distribuidor para Estados Unidos e Europa.

O CV se fixa como um importante ator do tráfico de drogas no contexto brasileiro, principalmente, com o intuito de financiar a fuga de presos políticos do Instituto Prisional de Cândido Mendes em Ilha Grande. Para que o tráfico de drogas continuasse prosperando, foi necessário o apoio, cada vez mais forte, da comunidade e dos políticos.

O crime organizado relaciona-se diretamente com política. No Brasil, "quando o Comando Vermelho assumiu o controle de quase $70 \%$ dos pontos-de-venda de drogas, se constituiu numa espécie de governo paralelo das comunidades pobres". ${ }^{42}$ No entanto, para se relacionar diretamente com a política e afirmar sua hegemonia, o CV matou "pelo menos treze líderes comunitários nos bairros pobres do Rio" ${ }^{43}$ Essa estratégia foi realizada para que os criminosos pudessem nomear novos líderes comunitários, já que "as associações de moradores são interlocutoras naturais com o poder público, são canais de negociação dos interesses locais". ${ }^{44}$ Formou-se um sistema hegemônico dentro das favelas.

As prefeituras são dividas em regiões administrativas - e dificilmente um administrador regional estaria disposto a receber um traficante para discutir as necessidades do morro, mesmo que ele fosse da maior representatividade. Mas - com toda a certeza - esse mesmo administrador receberia de bom grado o presidente de uma associação de moradores, ainda que apoiado pelo crime. Ou seja: as entidades comunitárias podem oferecer uma fachada legal para a atuação das quadrilhas. Obtendo benefícios, o tráfico de drogas amplia a influência política sobre a favela ${ }^{45}$.

Em uma cidade como o Rio de Janeiro, as eleições para deputado, vereador, prefeito, governador, entre outros, passam necessariamente pelas entidades comunitárias representativas das favelas, já que são milhões de moradores em comunidades carentes,

\footnotetext{
${ }^{42}$ AMORIM, Carlos, op. cit., p. 280.

${ }^{43}$ Idem.

${ }^{44}$ Ibidem. p. 281.

${ }^{45}$ Idem.
} 
e assim nenhum político despreza o apoio dos líderes comunitários. ${ }^{46} \mathrm{O}$ crime organizado sendo hegemônico nas comunidades passa a "influir nas tendências políticas da federação e adquire enorme poder de barganha". ${ }^{47}$ Desse modo, o CV pode ser considerado um influente ator da sociedade civil, pela sua responsabilidade na elaboração e difusão das ideologias, e os “donos do morro", intelectuais orgânicos.

O narcotráfico domina os negócios do $\mathrm{CV}$ e, desta forma, gera emprego para os moradores dos morros cariocas. Muitos dos que entram no mundo do tráfico de drogas começam cedo e são levados ao crime por vários motivos. O tráfico atrai crianças e adolescentes, as recruta, as seduz.

Os benefícios são as evidentes vantagens materiais, como dinheiro e acesso ao consumo, e são também os bens simbólicos e afetivos, como a sensação de importância e poder, o status, o sentimento de pertencimento a um grupo dotado de identidade - tudo isso significa valorização pessoal, reforço da auto-estima. ${ }^{48}$

Outra forma de influência é a visão de masculinidade, uma visão viril do indivíduo que se transforma em um poder de sedução para com as meninas do morro e também dos bairros nobres. ${ }^{49}$

O "dono do morro" é o juiz e o prefeito da área controlada, além de ser o principal investidor na favela, investindo nos próprios negócios e também em samba, educação, saneamento e moradia. ${ }^{50}$ Quase um "pão e circo" romano.

O crime organizado ocupa as lacunas de assistência social que o Estado vai deixando para trás, ao sabor da crise econômica ou da insensibilidade política. A dominação sobre as comunidades pobres passa quase que necessariamente por esse tipo de estratégia até porque o bandido mora na favela e é mais permeável às reivindicações do morador. A postura paternalista se mistura - até mesmo se confunde com a aplicação da 'lei do cão'. O favelado também compreende isso, numa aceitação de que a violência é natural num segmento da sociedade que já vive mesmo sem leis. A marginalização produz esse fenômeno social, ético e político. ${ }^{51}$

As organizações criminosas empregam, diretamente, sem salários fixos, milhões de pessoas sendo sua maioria constituída por crianças e adolescentes. Os "salários" pagos pelas organizações criminosas são mais atraentes que o salário oferecido em um

\footnotetext{
${ }^{46}$ Idem.

${ }^{47}$ Ibidem. p. 282.

48 ATHAYDE, Celso; MV Bill; SOARES, Luiz Eduardo. Cabeça de Porco. Rio de Janeiro: Objetiva, 2005. p. 285.

${ }^{49}$ Idem.

${ }^{50}$ AMORIM, Carlos, op. cit., p. 280.

${ }^{51}$ Ibidem. p. 353.
} 
emprego formal. Os indivíduos que fazem parte do crime organizado são atraídos também pelo consumismo capitalista: "rouba-se para desfrutar nível de vida parecido com o das elites privilegiadas, fora do alcance do poder aquisitivo dos pobres remediados e da classe média baixa" ${ }^{52} \mathrm{Na}$ verdade, podemos apontar como um dos maiores problemas o consumismo, já que a grande maioria dos jovens são impelidos a entrar para o tráfico de drogas no intuito de se inserirem em uma realidade onde possam adquirir os bens tão almejados pela nossa sociedade de consumo, como, por exemplo, tênis de marcas multinacionais, roupas de grife, eletrônicos de ultima geração, entre outros. A partir destes artifícios eles sentem o gostinho em utilizar as mesmas ferramentas que os playboys ${ }^{53}$ utilizam para seduzir garotas e para serem aceitos em grupos específicos. Portanto, a forma de sobrevivência do indivíduo desamparado, no mundo capitalista, é o mundo do crime e/ou o comércio ilícito.

O combate ao comércio ilícito por parte dos Estados torna-se cada vez mais difícil, já que, só no Brasil, a "economia subterrânea emprega e sustenta diretamente cerca de 30 milhões de pessoas". ${ }^{54}$ Uma verdadeira evolução da clandestinidade.

Grandes empresas, quando modernizam seus maquinários, enxugam seus gastos com mão-de-obra, demitindo grande parte de seus empregados, sem citar quando transferem suas fábricas para outros Estados, sempre visando maiores lucros. Dessa forma, gera uma massa de desempregados à procura de novos empregos. Muitas vezes esses empregos não aparecem, assim, os indivíduos procuram ganhar seu sustento na informalidade, trabalhando sem carteira assinada (caso do Brasil) ou entrando no mundo do comércio ilícito. "A economia informal capitalista é impiedosa: reproduz com maior brutalidade as injustiças sociais da economia informal, porque encontra-se acima dos controles sociais do Estado",55, nenhum traficante ou camelô entra na justiça trabalhista contra o seu "patrão".

Os Estados procuram de uma forma ou de outra diminuir e erradicar essa problemática, o meio utilizado para tanto são os acordos, tratados e protocolos internacionais. O primeiro tratado firmado pelo Brasil, sobre o tema, foi em $1882 \mathrm{com}$ a China. "O Tratado de Amizade, Comércio e Navegação, promulgado pelo Decreto $\mathrm{n}^{\circ}$

\footnotetext{
52 PROCÓPIO, Argemiro. "Narcotráfico e Sociedade". In: PROCÓPIO, Argemiro. Narcotráfico e Segurança Humana. São Paulo: LTr, 1999. p. 46.

${ }^{53}$ Gíria utilizada para indicar jovens com alto poder aquisitivo.

${ }^{54}$ PROCÓPIO, Argemiro, op. cit., p. 25.

${ }^{55}$ Ibidem. p. 34.
} 
8.651, trata, entre outras medidas, da proibição do comércio de ópio entre ambos os países". 56

Convenções também foram firmadas como:

- Convenção para Repressão contra Tráfico Ilícito de Drogas Nocivas de 1936, firmada no âmbito da extinta Liga das Nações;

- Convenção Única Sobre Entorpecentes de 1961. Nela foi incluída uma lista de entorpecentes sujeitos à fiscalização e criada a Junta Internacional de Fiscalização de Entorpecentes (JIFE), que "é um órgão independente que monitora a implementação das convenções da ONU sobre o controle internacional de drogas" ${ }^{\text {,57; }}$

- Convenção das Nações Unidas sobre Substâncias Psicotrópicas de 1971. Esta convenção teve uma abordagem mais social com relação ao combate às drogas, ao colocar em cena que o grande prejudicado é o usuário, criando meios aos países signatários de combate ao uso abusivo de drogas por meio da Cooperação Internacional;

- Convenção contra o Tráfico Ilícito de Entorpecentes e Substâncias Psicotrópicas de 1988. Nela, os "participantes (...) reconheceram que a erradicação do tráfico ilícito é de responsabilidade coletiva dos Estados e que para este fim era necessária ação coordenada no marco da cooperação internacional." ${ }^{58}$; e

- Convenção das Nações Unidas contra o Crime Organizado Transnacional de 2000. Em seu artigo $1^{\circ}$ coloca: "o objetivo da presente Convenção consiste em promover a cooperação para prevenir e combater mais eficazmente a criminalidade organizada transnacional". 59

Todos esses esforços mostram como as organizações criminosas, incluindo aí o Comando Vermelho, influenciaram o caminhar da ordem mundial e dos Estados, uma vez que as forças sociais fizeram parte desse círculo de influências coxianas. A partir do momento em que a ordem mundial sente-se ameaçada por essas forças sociais, medidas são tomadas para contê-las, como é o caso das convenções no âmbito internacional e das leis no que tange às políticas internas dos Estados.

\footnotetext{
${ }^{56}$ Ibidem. p. 69.

${ }^{57}$ Disponível em: 〈http://www.unodc.org/brazil/pt/jife.html〉. Acesso em 15 de agosto de 2006.

${ }^{58}$ PROCÓPIO, Argemiro, op. cit., p. 123.

${ }^{59}$ Convenção das Nações Unidas contra o Crime Organizado Transnacional. Art. $1^{\circ}$.
} 
No entanto, não se pode esquecer que essas forças sociais são inerentes à sociedade civil, que é a peça motora da opinião pública. Para que as idéias sejam propagadas é necessária a presença dos intelectuais orgânicos que propagam sua idéias por meio do senso comum para que a comunicação entre os intelectuais e a massa se torne compreensível.

Podemos citar o caso da formação da organização criminosa paulista, chamada Primeiro Comando da Capital (PCC), que foi influenciada pelo CV, em que um grande líder preparou o terreno para a formação de mais uma organização criminosa no país. Willian da Silva Lima, conhecido como Professor, foi um dos fundadores do Comando Vermelho, foi transferido para o presídio de Bangu Um, onde recebeu um prêmio, cumprir sua pena em regime semi-aberto. Porém, depois de um período seu recurso foi recusado. Sabendo que quando voltasse iria ser "trancafiado", decidiu fugir com sua mulher para São Paulo, em julho de 1986, "em busca de começar uma vida nova". 60

O professor viveu durante quatro anos em São Paulo. "No dia 11 de março de 1993 o jornal Folha de São Paulo publicou matéria com chamada na primeira página: Comando Vermelho invade São Paulo".61 A reportagem relata que o Comando Vermelho estava comprando postos de gasolina e casas lotéricas, para lavagem de dinheiro do tráfico de drogas, além de firmar pactos com banqueiros paulistas do jogo do bicho.

Em 1995, um time de futebol dentro da Casa de Custódia de Taubaté, o Comando da Capital, ganha todos os campeonatos. A habilidade com a bola e os títulos renderam a eles fama e a liderança da prisão. Com um respeito generalizado, eles começam a observar os problemas dos cárceres de São Paulo. Fátima de Souza, repórter da Folha de São Paulo relata:

Geléia (José Márcio Felício), amigo do coração e do crime de Cesinha (César Augusto Roriz), acompanhou o discurso inflamado do outro e acompanhou naquela noite:

- Como vamos chamar esse novo 'time'?

- Primeiro Comando da Capital - batizou Cesinha, usando parte do nome do time que os consagrara na cadeia.

Nascia ali o PCC. Em poucos dias as idéias foram colocadas no papel. E até um Estatuto foi manuscrito. Prometiam fidelidade, luta até a morte pelos direitos jamais respeitados dos detentos do país.

Foi rápido: nas rebeliões, lençóis brancos apareciam com três letras (PCC) do partido do crime. Subestimado pelo governo, que não

\footnotetext{
${ }^{60}$ AMORIM, Carlos, op. cit., p. 339.

${ }^{61}$ Ibidem. p. 345.
} 
conheça a realidade das cadeias, o PCC criou raízes em todo o sistema carcerário paulista. Nas prisões, diretores ultrapassados, da época da repressão (no regime militar), tentavam resolver o problema da maneira em que foram doutrinados: porretes, choques, água fria, porrada... Não foi suficiente. Em menos de três anos, já eram três mil. Em menos de dez anos, 40 mil... ${ }^{62}$

Dessa forma, vimos que a liderança do PCC foi firmada a partir do senso comum, ou seja, de uma forma de expressão e status muito comum dentro do Brasil que é o futebol. Além do mais, o contexto histórico favorecia, pois, em 1994, a seleção brasileira de futebol foi tetra campeã mundial. O futebol estava em alta.

A grande reivindicação do PCC é a melhoria das condições dos presos, já que no "Brasil seus aproximadamente 170 mil presos lotam dezenas de presídios, cuja capacidade máxima mal daria para abrigar 74 mil deles". ${ }^{63}$ Os indivíduos são presos porque não estão aptos a viver em sociedade. Assim, os presídios são locais para que os detentos possam se re-socializar, porém a falta de segurança entre os presos, a superlotação das celas, a não liberação de presos que já cumpriram a pena, a falta de higiene etc, são os fatores que levam à união para a sobrevivência. Dessa maneira, um novo acordo é firmado dentro das cadeias para a manutenção da paz e das igualdades, não mais entre os indivíduos e o Estado, mas entre aqueles e as organizações criminosas que atuam dentro dos presídios brasileiros. Os presos, que deveriam ser reeducados para uma posterior re-inserção na sociedade, saem com "doutorado" em crime.

O desinteresse do Estado em descobrir e estudar as causas que levam o indivíduo ao mundo do crime é somado a fatores anteriores como, por exemplo, o descaso com a educação, as desigualdades sociais, a falta de oportunidades, entre outros. Medidas de coerção imediatistas que repercutem rapidamente e que tem efeito a curto prazo na sociedade são mais viáveis e bem vistas que ações a serem alcançadas a longo prazo. Entretanto, a cultura que temos que desenvolver é a de conscientização de que as medidas de longo prazo serão mais efetivas e sustentáveis.

Enquanto isso, o PCC continua se organizando, as rebeliões nos presídios, os ataques em massa contra o governo e contra a sociedade são magistralmente orquestrados. Quando uma rebelião estoura em um presídio em São Paulo, podemos esperar que em questão de minutos novas rebeliões irão acontecer em todo o estado. $\mathrm{O}$ que mais se questiona é como que eles são tão organizados? Essa resposta somente o

\footnotetext{
${ }^{62}$ Folha de São Paulo Apud AMORIM, Carlos, op. cit., pp. 374-375.

${ }^{63}$ PROCÓPIO, Argemiro, op. cit., p.44.
} 
tempo nos dará, porque para que uma rebelião do porte das que acontecem no Brasil ocorra, é necessário que existam líderes espalhados por todos os presídios e que esses estejam ligados a um único líder. Atualmente, a mídia indica Marcos Willian Herbas Camacho, o Marcola, como líder do PCC.

A inserção de novos indivíduos dentro dessas organizações criminosas são bem relatadas na música onde a voz dos excluídos pode ser ouvida. No início do CV, o tipo de canção que retratava a vida nas comunidades de baixa renda era o samba, hoje, ele ainda permeia essa realidade, porém, o que mais está em ascensão são as vertentes musicais do hip-hop, rap e funk. Com letras que retratam a realidade em que vivem, são influentes na vida do indivíduo, já que estes se identificam com as canções. Um grande exemplo é a musica "Soldado do Morro" do cantor de rap MV Bill. Abaixo seguem trechos da música:

\author{
(...) Qualquer roupa agora eu posso comprar \\ Tem um monte de cachorra querendo me dar \\ De olho grande no dinheiro esquecem do perigo \\ A moda por aqui é ser mulher de bandido (..) \\ Sou combatente coração vermelho \\ Minha mina de fé ta em casa com o meu menor \\ Agora posso dar do bom e melhor \\ Varias vezes me senti menos homem \\ Desempregado meu moleque com fome \\ É muito fácil vir aqui me criticar \\ A sociedade me criou agora manda me matar \\ Me condenar e morrer na prisão \\ Virar noticia de televisão \\ Seria diferente se eu fosse mauricinho \\ Criado a sustagem e leite ninho \\ Colégio particular depois faculdade \\ Não é essa minha realidade \\ Sou caboquinho comum com sangue no olho \\ Com ódio na veia soldado do morro(....). ${ }^{64}$
}

A cultura é uma das únicas formas de demonstrar para a sociedade em geral o que acontece na periferia. Fica claro nessa canção a problemática da questão. As letras são feitas a partir de experiências vividas em seu dia-a-dia. O primeiro trecho da canção demonstra qual a tendência das grandes cidades, em que as garotas encontram nos bandidos a figura do "gangster" tão valorizada pelos filmes, além de serem os únicos indivíduos na favela com um poder aquisitivo muito superior ao dos demais moradores.

\footnotetext{
${ }^{64}$ Disponível em: <http://mv-bill.letras.terra.com.br/letras/68014/>. Acesso em 22 de setembro de 2006.
} 
O interesse na trilha deste caminho por parte dos demais jovens fortalece-se a partir da grande muralha entre a morro e o asfalto, que é extremamente difícil de ser transposta.

Desse modo, as informações que são passadas à grande maioria da população, normalmente, são equivocadas ou até manipuladas. Um menino de rua em uma grande cidade é taxado de bandido, os habitantes de comunidades carentes são taxados de criminosos. "Quem é pobre não possui carro, infra-estrutura e sequer 'boa aparência' para usufruir em segurança dos frutos do crime" ${ }^{65}$. O senso comum no combate aos criminosos é caracterizado pelo combate direto na periferia, porém, não são eles que têm o privilégio de desfrutar dessa riqueza.

Portanto, as dificuldades que os Estados encontram para combater o crime organizado são inúmeras. No caso brasileiro, a legislação é frágil, há omissão, negligência e cumplicidade do poder público em diversos níveis da administração que vão desde agentes carcerários, passando por policiais e chegando até desembargadores dos tribunais superiores, além de congressistas.

No plano internacional, os Estados se vêem constantemente pressionados para que os gastos públicos sejam limitados, viabilizando uma melhor administração da máquina pública. Assim, as organizações criminosas saem ganhando com a alta burocracia do serviço público, onde cada órgão tem limites de atuação bem definidos. Em contrapartida, o crime organizado ultrapassa fronteiras e tem suas atividades exercidas com mais flexibilidade. A existência de limites para atuação por parte da sociedade política e a inexistência de fronteiras para atuação do crime organizado acabam sendo um grande obstáculo para o combate às organizações criminosas.

Michael Focault indaga qual seria a importância da máquina estatal caso os criminosos, por ele chamado de delinqüentes, não existissem:

A sociedade sem delinqüência foi um sonho do século XVIII que depois se acabou. A delinqüência era por demais útil para que se pudesse sonhar com algo tão tolo e perigoso como uma sociedade sem delinqüentes. Sem delinqüência não há polícia. O que torna a presença policial, o controle do policial tolerável pela população se não houver medo do delinqüiente? A instituição tão pesada que é a polícia não se justifica senão por isso. Aceitamos entre nós esta gente de uniforme, armada enquanto nós não temos o direito de o estar, que nos pede documentos, que vem rondar nossas portas. Como isso seria aceitável se não houvesse os delinqüentes? ${ }^{66}$

\footnotetext{
${ }^{65}$ PROCÓPIO, Argemiro, op. cit., p. 45.

${ }^{66}$ FOUCAULT, Michel. Microfísica do Poder. 4 ed.. Rio de Janeiro: Edições Graal, 1984, pp. 137-138 Apud Ibidem. p. 68.
} 
Fica claro que sem o crime a sociedade política perde a sua principal função, a garantia da segurança da sociedade civil. Para que um exista é necessária a presença do outro. Essas formas atuam em conjunto onde uma depende da outra.

The Chinese concepts of yin and yang fit well with the historical relationship of established society (yang) and secret society opposition (yin), a relationship in which both are bound together, the one and the other achieving alternating pre-eminence through the movement of history in which neither the one nor the other is ever totally eliminate. ${ }^{67}$

Quando uma deixa de existir, não há necessidade da existência da outra. Ao mesmo tempo, as forças sociais cobram um combate ao crime por parte do ator principal, o Estado. Uma afirmação um tanto quanto equivocada no sentido que essas forças se esquecem que fazem parte da sociedade civil e que, juntamente com a sociedade política, formam o Estado.

${ }^{67}$ COX, Robert. "The covert world" In: COX, Robert; SCHECHTER, Michael G. The Political Economy as a Plural World: Critical reflections on power, morals and civilization. London: Routledge, 2002. p.127. 


\section{CONCLUSÃO}

A primeira consideração que deve ser feita sobre este estudo é a relevância do pensamento de Cox, as estruturas históricas, que foram essenciais para o entendimento acerca do tema. Ficou claro que quando há modificações em qualquer uma das esferas das estruturas históricas (sejam elas a ordem mundial, as formas de Estado e as forças sociais) as outras esferas são diretamente influenciadas.

Para se ter uma visão macro do sistema é necessário utilizar as estruturas históricas de Cox, demonstrando que as ordens mundiais são extremamente relevantes para se entender as ações dos criminosos, as quais são refletidas nas posições políticas dos Estados.

A segunda parte do artigo tratou de responder a seguinte questão: Como o Comando Vermelho é formado por elementos constantes na ordem mundial e no Estado brasileiro? Ao final da segunda parte ficou claro que o Comando Vermelho foi formado a partir do momento em que a ordem mundial seguia uma tendência, que foi fundamental para o entendimento das atitudes políticas a serem tomadas. Essas, por sua vez, foram fundamentais para a modificação das forças sociais e para o nascimento de novos atores influentes na sociedade civil.

É nítida a inter-relação entre as esferas apresentadas por Cox. O Comando Vermelho apresenta-se no cenário mundial no momento em que essas ordens mundiais modificam outras formas de Estado e formam novas forças sociais. Quando há união entre essas forças sociais, uma grande rede de tráfico de drogas se estabelece, influenciando, assim, o desenvolvimento dos Estados e da ordem mundial.

A terceira parte do artigo procura responder o seguinte questionamento: Como a atuação do Comando Vermelho gera mudanças na Ordem Mundial e no Estado brasileiro? Chega-se à conclusão de que as modificações nas forças sociais são refletidas nas políticas, por parte dos Estados, de combate às organizações criminosas e em convenções internacionais para encontrar um caminho para a solução desse problema. O consenso que se chega é que, com a cooperação internacional, os Estados terão mais subsídios no combate ao crime e na reinserção dos indivíduos que fazem parte de organizações criminosas como o Comando Vermelho.

Ao término da última parte é mostrado como são expostos na cultura os reflexos das modificações das forças sociais. A música é um dos principais meios de expressão das condições de vida nas sociedades menos favorecidas. É lúcida a idéia de que o 
Estado está estritamente ligado ao papel do combate ao crime e, assim, sem o crime, qual será o papel do Estado?

Ficou claro ainda que há uma relação direta entre o que é considerado lícito com o que é considerado ilícito e com as relações entre o Estado e o crime organizado, já que um é dependente do outro, uma vez que a inexistência de um acarretará no fim do outro.

Dessa forma, podemos afirmar que o comércio ilícito é a principal mazela dos Estados, um ator capaz de modificar tanto as forças sociais quanto as ordens mundiais. Apesar de fatores sociais serem importantes para o entendimento do crime organizado, um fator ainda é o principal, o dinheiro, que é o que promove a criação de novas organizações criminosas, a entrada de novos indivíduos e o enriquecimento de outros tantos. O comércio ilícito é o que mais gera lucros hoje, já que não existem impostos a serem pagos e os preços são estipulados pelos próprios criminosos. 


\section{REFERÊNCIAS BIBLIOGRÁFICAS}

AMORIM, Carlos. CV-PCC: a irmandade do crime. 6 ed. Rio de Janeiro: Record, 2005.

ATHAYDE, Celso; MV Bill; SOARES, Luiz Eduardo. Cabeça de Porco. Rio de Janeiro: Objetiva, 2005.

BUENO, Clodoaldo; CERVO, Amado Luiz. História da Política Exterior do Brasil. 2 ed. Brasília: Editora Universidade de Brasília, 2002.

COUTINHO, Carlos N. Gramsci: um estudo sobre o seu pensamento político. Rio de Janeiro: Civilização Brasileira, 2003.

COX, Robert; SCHECHTER, Michael G. The Political Economy as a Plural World: Critical reflections on power, morals and civilization. London: Routledge, 2002.

DUROSELLE, Jean-Baptiste. Todo império perecerá. Brasília: Editora Universidade de Brasília: São Paulo: Imprensa oficial do Estado, 2000.

FAUSTO, Boris. História Concisa do Brasil. 2 ed. São Paulo: Editora da Universidade de São Paulo, 2006.

GILL, Stephen. Gramsci, Historical Materialism and International Relations. Cambridge: University Press, 1993.

GOMES, Luiz Flávio. Crime Organizado: enfoque criminológico, jurídico (lei 9.034/95) e político-criminal. 2 ed. São Paulo: Editora Revista dos Tribunais, 1997.

GRIFFITHS, Martin. 50 Grandes Estrategistas das Relações Internacionais. São Paulo: Contexto, 2004. 
LILLEY, Peter. Lavagem de dinheiro: negócios ilícitos transformados em atividades legais. São Paulo: Editora Futura, 2001.

LUPO, Salvatore. História da Máfia: das origens aos nossos dias. Tradução Álvaro Lorencini. São Paulo: Editora UNESP, 2002.

MAIA, Rodolfo Tigre. O Estado Desorganizado Contra o Crime Organizado. Rio de Janeiro: Editora Lúmen Júris, 1997.

MENDRONI, Marcelo Batlouni. Crime Organizado: aspectos gerais e mecanismos legais. São Paulo: Editora Juarez de Oliveira, 2002.

NAIM, Moisés. Ilícito: o ataque da pirataria, da lavagem de dinheiro e do tráfico a economia global. Tradução de Sérgio Lopes. Rio de Janeiro: Jorge Zahar Editora, 2006.

PORTELLI, Hugues. Gramsci e Bloco Histórico. Rio de Janeiro: Paz e Terra, 1977.

PROCÓPIO, Argemiro. Narcotráfico e Segurança Humana. São Paulo: LTr, 1999.

RICHARDS, James R.. Transnational criminal organizations, cybercrime \& money laundering: a handbook for law enforcement officers, auditors, and financial investigators. Florida: CRCPRESS, 1998.

SAFARTI, Gilberto. Teoria das Relações Internacionais. São Paulo: Saraiva, 2005.

SILVA, Marco Antonio de Meneses. "Teoria Crítica em Relações Internacionais" In: Contexto Internacional, vol. 27, $\mathrm{n}^{\circ}$ 2, julho/dezembro de 2005.

SZNICK, Valdir. Crime Organizado Comentários. São Paulo: Livraria e Editora Universitária de Direito Ltda, 1997.

Fontes eletrônicas: 
<http://www.ufrgs.br/tramse/classicos/2004 0516 class.html > . Acesso em: 29 de junho. de 2006.

<http://www.espacoacademico.com.br/034/34coliveira.htm $>$. Acesso em: 15 de abril de 2006.

〈http://www.mj.gov.br/drci/documentos/ENCLA\%202006.pdf $>$. Acesso em: $15 \mathrm{de}$ março de 2006.

$<$ http://Jus Navigandi.-Doutrina.Crime organizado.htm>. Acesso em: 15 de março de 2006.

< http://www.ojogodobicho.com/historia.htm >. Acesso em: 16 de março de 2006.

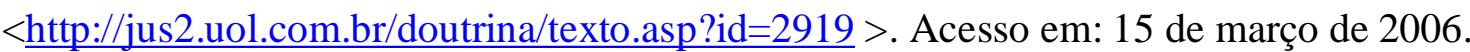

<http://purl.pt/711/1/china/ch-07.html > . Acesso em: 17 de março de 2006.

<http://www.unodc.org/brazil/pt/jife.html > . Acesso em: 15 de março de 2006.

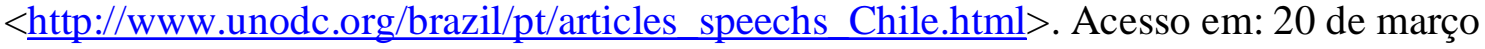
de 2006.

<www.unoddc.org >. Acesso em: 20 de março de 2006.

<http://kalashnikov.guns.ru/>. Acesso em: 5 de junho de 2006.

<http://www1.folha.uol.com.br/folha/cotidiano/ult95u125482.shtml $>$. Acesso em: $20 \mathrm{de}$ agosto de 2006.

$\langle\underline{\text { http://mv-bill.letras.terra.com.br/letras/68014/> }}$. Acesso em: 22 de setembro de 2006. 